\title{
Comparison of some important dairy traits of crossbred cows at Baghabarighat milk shed area of Bangladesh
}

\author{
MS Hossen* ${ }^{1}$, S.S. Hossain, AKFH Bhuiyan, MA Hoque, MAS Talukder
}

Department of Animal Breeding and Genetics, Bangladesh Agricultural University, Mymensingh 2202, Bangladesh; 'Bangladesh Milk Producers' Cooperative Union Limited (Milk Vita), Dugdha Bhaban, 139-140 Tejgaon, Dhaka 1208, Bangladesh

\begin{abstract}
Data on 3637 cows of seven genetic groups at Baghabarighat milk shed area during the period from 1991 to 2000 were analyzed. The genetic groups were Pabna Milking Cows (PMC), $1 / 2$ Sahiwal $\times 1 / 2$ PMC $(\mathrm{SL} \times \mathrm{PMC}), \quad 1 / 2$ Frisian $\times 1 \frac{1}{2} \mathrm{PMC} \quad(\mathrm{FN} \times \mathrm{PMC}), \quad 1 / 2$ Australian Friesian Sahiwal $\times 1 / 2 \mathrm{PMC} \quad(\mathrm{AFS} \times \mathrm{PMC})$, $1 / 2$ Sahiwal $\times 1 / 4$ Friesian $\times 1 / 4$ PMC $\quad[S L(F N \times P M C)], \quad 1 / 2 F$ riesian $\times 1 / 4$ Sahiwal $\times 1 / 4$ PMC $\quad[F N(S L \times P M C)]$ and $1 / 2$ Friesian $\times 1 / 4$ ] ersey $\times 1 / 4$ PMC [FN(J R $\times$ PMC) ]. The purpose of this study was to compare the productive (birth weight, lactation length, lactation yield, fat\% and SNF\%) and reproductive (age at first service, service per conception, postpartum heat period and calving interval) traits of different crossbred cows. The highest birth weight of calves was obtained as $29.78 \mathrm{~kg}$ in AFS XPMC, lactation yield as 2225.52 liters in $F N(J R \times P M C)$, fat\% as 4.48 in $\mathrm{SL} \times \mathrm{PMC}$ and SNF\% as 8.10 in FN(SL×JR). The longest lactation length was observed as 305.18 days in AFS $\times$ PMC. The shortest age at first service was observed as 26.83 months in $\mathrm{FN}(\mathrm{PMC} \times \mathrm{SL})$, postpartum heat period as 133.23 days in $\mathrm{PMC}$ and calving interval as 414.90 days in PMC. The lowest service per conception was found to be 1.22 in PMC cows. The high genetic variability of birth weight, lactation yield, fat and SNF\% indicated that there are good opportunities for genetic improvement of these traits through selection. From the results, it is evident that the level of production of different crossbred cows found to be higher but important reproductive traits were significantly better on PMC. Thus it may be concluded that for long term sustainable development and conservation program for PMC should be initiated alongside with that of crossbred in this particular study area.
\end{abstract}

Key words: Pabna milking cows, phenotypic value, generation

Bangladesh Animal Husbandry Association. All rights reserved.

Bang. J. Anim. Sci. 2012. 41 (1): 13-18

\section{I ntroduction}

Baghabarighat milk shed area is famous as bathan based largest cooperative milk pocket in Bangladesh. The people of these areas traditionally involved in rearing high yielding dairy cows long before the partition of India. The interested persons of these areas brought some Red Sindhi and Multani bulls from India for natural breeding of cows of these areas. Lord Linlithgo, the then British Vice Roy brought some Hariana and Red Sindhi bulls from the northern part of India and distributed for natural breeding in the year 1936 (Udo et al. 1990). Through many generations of upgrading of local cows by natural breeding with Hariana and Red Sindhi bulls, the cattle of these areas became a notable dairy type popularly known as Pabna milking cows (PMC).

Bangladesh Milk Producers Co-operative Union Limited (BMPCUL) was established in the year
1973 with the emphasized initiative of the then Government in co-operative form. With passage of time, BMPCUL undertook a further program for the improvement of PMC cows through crossing with Sahiwal (SL), Friesian (FN), Australian Friesian Sahiwal (AFS) and Jersey (J R) breeds since 1987 using frozen semen. The frozen semen was imported from New Zealand, Pakistan, Australia, India and also from USA. As a result, temperate dairy inheritance levels of the cattle of these areas have been elevated. Among the available genetic groups, seven were considered as $\mathrm{PMC}, \mathrm{SL} \times \mathrm{PMC}, \mathrm{FN} \times \mathrm{PMC}$, AFS $\times P M C, \quad S L(F N \times P M C), \quad F N(S L \times P M C)$ and $\mathrm{FN}(\mathrm{J} \times \mathrm{PMC})$ in the present study for conducting the current piece of research.

Performances of crossbreds of PMC with SL and FN have been evaluated by some researchers (Islam et al. 1977; Hoque et al. 1999). However, present study covered the estimation of phenotypic values of important dairy traits 


\section{Performance of crossbred cows}

(e.g., birth weight, lactation length, lactation yield, fat\%, SNF\%, age at first service, service per conception, postpartum heat period and calving interval etc.) with larger number of data and all available genotypes of Baghabarighat milk shed area.

\section{Materials and Methods}

The present study was conducted at the Baghabarighat milk shed area under Bangladesh Milk Producers' Co-operative Union Limited (BMPCUL) in Bangladesh. The Baghabarighat milk shed area is a promising avenue for intensive dairy production and it is famous for unique Bathan system; a model of dairy development in Bangladesh along with many developing countries with similar agrolivestock production system (Hoque et al. 1999). Cows were mostly grazed on the native and cultivated pastures in Bathan areas during the summer. From November to May milking cows are usually grazed on this Bathan area in a rotation system. In addition, concentrate feed at the rate of 3 to $5 \mathrm{~kg}$ and straw at the rate of 4 to $5 \mathrm{~kg}$ was fed per cow per day throughout the year. During the rainy season cows were completely confined and raised in homestead open shed of the owner. Stall-feeding was done mainly with hay as a basal diet supplemented with concentrate mixture during the rainy season. The recorded temperature of the study area averaged $36.66^{\circ} \mathrm{C}$ in summer and $7.25^{\circ} \mathrm{C}$ in winter.

Lactating cows were milked manually twice a day. Calves were kept separated over night before the milking was performed. Herd management and feeding practices were maintained almost equally throughout the study period.

\section{The cows and data collection}

The data were collected on 3637 cows of seven different genetic groups. Most of the cows at study area were of PM and graded type. The data for this study were collected on 3637 cows of seven different genetic groups owned by farmers. For each cow a separate record sheet was maintained. All the cows were ear-tagged for identification and collection of individual performance records of interest. The weights of newborn calves were recorded in kilogram within 6 to 12 hours of birth. The total quantity of collected milk throughout the lactation period was defined as lactation yield of the cow. Each cow was hand milked on every $30^{\text {th }}$ day (test day) up to last day of lactation. The first milk production was recorded at the $10^{\text {th }}$ day of parturition and lactation yield was calculated by summing up the milk of test days (excluding first nine days).

The first nine days were needed for adjustment of suckling and proper milking of the cows. The lactation yield of individual cow in first lactation period was estimated as

$$
\mathrm{LY}_{(\mathrm{k})}=30 \times \sum_{\mathrm{i}=l}^{n} \mathrm{Ti}
$$

where $L Y_{(k)}=$ lactation yield of $k^{\text {th }}$ cow; $\mathrm{Ti}=$ milk yield of the $i^{\text {th }}{ }^{\text {th }}$ test day $(i=1,2, . . n)$ assuming test day milk yield as a true representative of 30 days (Mantysaari, 2002).

Milk sample was collected from each cow on test day from morning and evening milking. The composite sample was tested to determine fat $\%$ from the date of first milking to the date of last milking. All milk samples were tested in the quality-testing laboratory. The SNF \% was also estimated from the composite sample and was calculated using the following formula:

$$
\mathrm{SNF} \%=\frac{\mathrm{CLR}}{4} \times 0.2 \times \text { Fat } \%+0.14
$$

where CLR $=$ Corrected lactometer reading

The age at which a heifer was first served was defined as age at first service. The age at first service was recorded on individual heifers in months. Services per conception were referred to as the number of insemination required for each successful conception. Conception was confirmed by pregnancy diagnosis through rectal palpation. The time between parturition and the first heat following parturition was termed as postpartum heat period and expressed in days. Days between two successive calving were defined as calving interval. In the present study, the interval between first and second calving was regarded as calving interval and expressed in days.

\section{Data analyses and statistical models}

The collected data were analyzed with Generalized Linear Model (GLM) procedure of Statistical Analysis System (SAS 1991) computer package. The least squares analysis of variance and Least Significant Difference 
(LSD) were done with the help of SAS. The statistical model to describe the traits was:

$Y_{i j k l}=\mu+G_{i}+B_{j}+L_{k}+e_{i j k l}$

where $Y_{i j k l}=$ the $n^{\text {th }}$ individual record; $\mu=$ common mean; $G_{i}=$ effect of $i^{\text {th }}$ genetic group $(i=1-7) ; B_{j}=$ effect of the $j^{\text {th }}$ birth year $(j=$ 1991-2000); $L_{k}=$ effect of $k^{\text {th }}$ generation $(k=$ 1-3); $\mathrm{e}_{\mathrm{ijkl}}=$ random error.

\section{Results and Discussion}

The effects of genetic groups on different productive traits are presented in Table 1. Birth weight of calves is regarded as one of the most important indicators for improving future performance. Significant $(p<0.001)$ variation in the birth weight of female calves was observed among crossbreds. The differences in birth weight of calves between $\mathrm{PM}$ and $\mathrm{PM} \times \mathrm{SL}$ dams and also among $\mathrm{AFS} \times \mathrm{PMC}, \mathrm{FN}(\mathrm{PM} \times \mathrm{SL})$ and $F N(J R \times P M C)$ dams were statistically nonsignificant $(p>0.05)$. AFS $\times P M C, F N(P M \times S L)$ and $F N(J R \times P M C)$ dams produced heaviest calves followed by $\mathrm{SL}(\mathrm{PM} \times \mathrm{FN}), \mathrm{PM} \times \mathrm{FN}, \mathrm{PM} \times \mathrm{SL}$ and PM cows, respectively.

The lowest birth weight for PMC (also SLXPMC) might be attributed to the lower genetic potential than the crosses of exotic breeds. Present study reveals that higher degree of FN genotype had the association with higher birth weight of calves especially when three way crossing was made. Padua and Silva (1996) and Gunawardena and Pushpakumara (1998) concluded that birth weight of calves is significantly affected by the genotype of sire and dam. Heavier birth weight of calves generally accelerates survivability, subsequent growth and attainment of early sexual maturity of the individuals. The mean birth weight of calves of PMC in the study was slightly higher than the findings of Udo et al. (1990) and Hoque et al. (1999), who reported birth weight for PMC calves to be 15.60 and $17.92 \mathrm{~kg}$, respectively for the same genotype. According to Nahar et al. (1992) and Hoque et al. (1999) the average birth weight of PMC $\times F N$ graded cattle as 22.00 and $22.50 \mathrm{~kg}$, respectively, which was lower than the results of the present study. Khan et al. (1992) reported that the mean birth weight of SL cross calves to be $20.04 \mathrm{~kg}$. Husain and Mostafa (1985) also stated that the birth weights of SL cross calves were 36.10 and $37.90 \mathrm{~kg}$ under rural and urban condition, respectively.
Table 1 reveals that lactation length of cows of different genetic groups differed significantly $(p<0.001)$. The lactation length followed a hierarchical order of AFS $\times$ PMC $>F N(S L \times P M C)>$ $\mathrm{SL}(\mathrm{PMC} \times \mathrm{FN})>\mathrm{FN}(\mathrm{R} \times \mathrm{PMC})>\mathrm{PMC} \times \mathrm{FN}>\mathrm{PMC} \times$ $S L>P M C$ distinctively in its length. The PMC had the lowest value for lactation length and AFS $\times$ PMC had the highest one. This discrepancy was mainly brought about by genetic and some non-genetic factors. Hossain et al. (2002) reported 249, 287 and 288 days as lactation length of local, SN and SL cows, respectively, which neighbored around the figures of current study. Bhuiyan (1999) reported that the lactation length of $\mathrm{FN}$ cross cows was 309 days in Central Cattle Breeding and Dairy Farm of Bangladesh, which was slightly higher than the result of the present study.

Lactation yield (Table 1 ) of cows of different genetic groups differed significantly $(p<0.001)$. The highest lactation yield was found for cows in genetic group $F N(J R \times P M C)$ and in AFS $\times P M C$, while the lowest value was found for cows in genetic group PMC. Literature concerning comparative lactation production between $\mathrm{FN}(\mathrm{J} \times \mathrm{PMC})$ and $\mathrm{PMC}$ is in extreme paucity. The other groups showed their performance within the two extremes. Lactation yield of cows in genetic group AFS $\times P M C$ and $F N(J R \times P M C)$ was almost similar. The result indicates that lactation yield of cows increased with the increased level of temperate germplasm. This discrepancy might be mainly due to the differences in genetic factors. Similar significant effect was reported by several researchers (Bhuiyan and Sultana 1994; Deb 2004).

Table 1 shows that fat \% of cows of different genetic groups differed significantly $(p<0.001)$. The highest fat \% was found jointly in genetic group SLXPMC and PMC. The second highest values were recorded for $S L(P M C \times F N)$ and $P M C \times F N$ genetic group. These findings are in harmony with the findings of $4.6 \pm 0.11 \%$ by Rahman et al. (1987) and $4.5 \pm 0.2 \%$ by Chowdhury et al. (1994) for FN $\times$ SL cows. These higher values in fat $\%$ of milk might be attributed to the genetic and non-genetic factors. The difference in fat $\%$ among AFS $\times$ PMC, $F N(S L \times P M C)$ and $F N(J R \times P M C)$ was statistically non-significant $(p>0.05)$ and they gave milk with lowest fat $\%$ among the genetic groups studied. 


\section{Performance of crossbred cows}

The highest SNF\% was found jointly among genetic group $F N(J R \times P M C), F N(S L \times P M C)$ and AFS $\times$ PMC cows, whilst PMC and SLXPMC cows gave milk with lowest SNF\%. Significant difference was noted among genetic groups for $\mathrm{SNF} \%$ in milk. In the present study, it was observed that SNF\% ranged from 7.94 in PMC to 8.10 in $F N(J R \times P M C)$. The SNF\% of milk was slightly lower than that estimated by Islam et al. (1984) in FN $\times$ Local cows. The lowest SNF \% for PMC (also in SLXPMC) was mainly may be due to lower genetic merit than the exotic crossbreds. From the results, it was observed that SNF \% of milk was higher in temperate breed than others, which might be due to genetic reason alongside herd management systems adopted.

The age at first service of heifers differed significantly $(p<0.05)$ among genetic groups. The shortest age at first service of heifers was observed for genetic group FN (SLXPMC), while PMC took longest time to manifest age at first service. $F N(J R \times P M C)$ genetic group ranked second longest in the order in this regard. However, there is no significant $(p>0.05)$ difference observed among SLXPMC, $\mathrm{SL}(\mathrm{PMC} \times \mathrm{FN})$ and $\mathrm{AFS} \times \mathrm{PMC}$ genetic groups. The age at first service of heifers varied among genetic groups. The lowest age at first service was noticed in genetic group $\mathrm{FN}(\mathrm{SL} \times \mathrm{PMC})$. On the other hand, the longest age at first service of PMC signifies the low genetic potential particularly for this trait. From the present study, it was revealed that age at first service decreases with the increase of birth weight of heifers. The high variability of results [26.83 months in $F N(S L \times P M C)$ to 33.31 months in $\mathrm{PMC}$ ] among the genetic groups might be due to difference in genetic composition and level of exotic inheritance of heifers along with various non-genetic causes. Consistent superiority in birth weight and age at first service of genetic group $F N(S L \times P M C)$ signifies that this combination of inheritance proved its superiority over others. The significant differences in age at first service among genetic groups might be due to difference in genetic merit of the heifers along with feeding and management system followed. The lowest age at first service of heifers in genetic group FN ( $S L \times P M C)$ might be of immense usefulness in the concerned system of dairying. However, relationship of earlier age at first service with subsequent lifetime productivity needs to be investigated. The least squares means with their standard errors (SE) for different reproductive traits by different genetic groups are presented in Table 2.

Table 1. Productive traits of crossbred cows by different genetic groups

\begin{tabular}{lcccccc}
\hline $\begin{array}{l}\text { Genetic } \\
\text { groups }^{\dagger}\end{array}$ & $\mathrm{n}$ & $\begin{array}{c}\text { Birth weight* } \\
(\mathrm{kg})\end{array}$ & $\begin{array}{c}\text { Lactation length } \\
(\text { days })\end{array}$ & $\begin{array}{c}\text { Lactation yield } \\
(\text { liters })\end{array}$ & $\begin{array}{c}\text { Fat } \\
(\%)\end{array}$ & $\begin{array}{c}\text { SNF } \\
(\%)\end{array}$ \\
\hline $\mathrm{PMC}$ & 674 & $23.39^{\mathrm{d}} \pm 0.13$ & $256.93^{\mathrm{g}} \pm 1.23$ & $1367.38^{\mathrm{f}} \pm 12.67$ & $4.47^{\mathrm{a}} \pm 0.01$ & $7.94^{\mathrm{c}} \pm 0.01$ \\
$\mathrm{SL} \times \mathrm{PMC}$ & 659 & $23.96^{\mathrm{d}} \pm 0.13$ & $270.23^{\mathrm{f}} \pm 0.89$ & $1513.51^{\mathrm{e}} \pm 9.10$ & $4.48^{\mathrm{a}} \pm 0.01$ & $7.97^{\mathrm{c}} \pm 0.01$ \\
$\mathrm{FN} \times \mathrm{PMC}$ & 361 & $24.92^{\mathrm{c}} \pm 0.16$ & $281.76^{\mathrm{e}} \pm 1.56$ & $1747.29^{\mathrm{d}} \pm 16.03$ & $4.25^{\mathrm{b}} \pm 0.01$ & $8.01^{\mathrm{b}} \pm 0.01$ \\
$\mathrm{AFS} \times \mathrm{PMC}$ & 515 & $29.78^{\mathrm{a}} \pm 0.24$ & $305.18^{\mathrm{a}} \pm 1.83$ & $2223.76^{\mathrm{a}} \pm 29.16$ & $4.13^{\mathrm{c}} \pm 0.02$ & $8.06^{\mathrm{ab}} \pm 0.01$ \\
$\mathrm{SL}(\mathrm{FN} \times \mathrm{PMC})$ & 626 & $28.58^{\mathrm{b}} \pm 0.12$ & $294.52^{\mathrm{c}} \pm 1.18$ & $1957.60^{\mathrm{c}} \pm 12.17$ & $4.26^{\mathrm{b}} \pm 0.01$ & $8.02^{\mathrm{b}} \pm 0.01$ \\
$\mathrm{FN}(\mathrm{SL} \times \mathrm{PMC})$ & 441 & $29.61^{\mathrm{a}} \pm 0.15$ & $298.14^{\mathrm{b}} \pm 1.42$ & $2039.24^{\mathrm{b}} \pm 14.63$ & $4.13^{\mathrm{c}} \pm 0.01$ & $8.08^{\mathrm{a}} \pm 0.01$ \\
$\mathrm{FN}(\mathrm{J} \times \mathrm{PMC})$ & 361 & $29.30^{\mathrm{a}} \pm 0.16$ & $289.99^{\mathrm{d}} \pm 1.56$ & $2225.52^{\mathrm{a}} \pm 16.07$ & $4.12^{\mathrm{c}} \pm 0.01$ & $8.10^{\mathrm{a}} \pm 0.01$ \\
\hline
\end{tabular}

Table 2. Reproductive traits of crossbred cows by different genetic groups

\begin{tabular}{lccccc}
\hline $\begin{array}{l}\text { Genetic } \\
\text { groups }^{\dagger}\end{array}$ & $\mathrm{n}$ & $\begin{array}{c}\text { Age at first } \\
\text { service (months) }\end{array}$ & $\begin{array}{c}\text { Service per } \\
\text { conception (no.) }\end{array}$ & $\begin{array}{c}\text { Postpartum heat } \\
\text { period (days) }\end{array}$ & $\begin{array}{c}\text { Calving interval } \\
\text { (days) }\end{array}$ \\
\hline PMC & 674 & $33.31^{\mathrm{a}} \pm 0.11$ & $1.22^{\mathrm{c}} \pm 0.02$ & $133.23^{\dagger} \pm 1.51$ & $414.90^{\mathrm{e}} \pm 1.55$ \\
$\mathrm{SL} \times \mathrm{PMC}$ & 659 & $30.07^{\mathrm{c}} \pm 0.08$ & $1.23^{\mathrm{c}} \pm 0.01$ & $135.27^{\mathrm{e}} \pm 2.66$ & $420.93^{\mathrm{c}} \pm 2.72$ \\
$\mathrm{FN} \times \mathrm{PMC}$ & 361 & $27.50^{\mathrm{d}} \pm 0.14$ & $1.35^{\mathrm{b}} \pm 0.02$ & $147.85^{\mathrm{c}} \pm 2.02$ & $430.48^{\mathrm{b}} \pm 20.7$ \\
$\mathrm{AFS} \times \mathrm{PMC}$ & 515 & $28.31^{\mathrm{cd}} \pm 0.21$ & $1.52^{\mathrm{a}} \pm 0.03$ & $152.73^{\mathrm{ab}} \pm 2.97$ & $441.42^{\mathrm{a}} \pm 3.09$ \\
$\mathrm{SL}(\mathrm{FN} \times \mathrm{PMC})$ & 626 & $29.69^{\mathrm{c}} \pm 0.11$ & $1.38^{\mathrm{ab}} \pm 0.02$ & $139.11^{\mathrm{d}} \pm 2.10$ & $418.14^{\mathrm{d}} \pm 2.15$ \\
$\mathrm{FN}(\mathrm{SL} \times \mathrm{PMC})$ & 441 & $26.83^{\mathrm{e}} \pm 0.13$ & $1.42^{\mathrm{a}} \pm 0.02$ & $150.12^{\mathrm{b}} \pm 2.43$ & $431.02^{\mathrm{b}} \pm 2.49$ \\
$\mathrm{FN}(\mathrm{J} \times \mathrm{PMC})$ & 361 & $31.81^{\mathrm{b}} \pm 0.14$ & $1.43^{\mathrm{a}} \pm 0.03$ & $154.08^{\mathrm{a}} \pm 2.67$ & $434.57^{\mathrm{a}} \pm 2.73$ \\
\hline Means with different superscripts in the same column differ significantly (p<0.001); ${ }^{\dagger}$ PMC, Pabna milking
\end{tabular}


Service per conception of heifers of different genetic groups differed significantly $(p<0.001)$. The lowest service per conception was found in genetic group PMC and SLXPMC (Table 2). Maximum number of services per conception was required for $A F S \times P M C$, $F N(J R \times P M C)$, $\mathrm{FN}(\mathrm{SL} \times \mathrm{PMC})$ and $\mathrm{SL}(\mathrm{PMC} \times \mathrm{FN})$, while $\mathrm{PMC} \times \mathrm{FN}$ stood intermediate in position. It was observed that service per conception of heifers increased with the increase of exotic inheritance, which provides hints on their poor adaptation. Result of the present study closely agrees with the findings of Islam and Bhuiyan (1997). They found that service per conception was $1.23 \pm 0.17$ in JR cross, $1.46 \pm 0.19$ in J R $\times S N$ and $1.45 \pm 0.12$ in SLXPMC, $1.23 \pm 0.10$ in $1 / 4$ PMC $\times$ $3 / 4 \mathrm{SL}$ cows at Baghabarighat milk shed area. From the result, it was observed that minimum service required for $P M C$ and SLXPMC, while second minimum required for $\mathrm{PMC} \times \mathrm{FN}$ bearing the message of loosing fitness of exotic germplasm at higher level in present condition.

The lowest postpartum heat period was observed in genetic group PMC, the second lowest of that was found in genetic group SLXPMC. The highest value was found in genetic group $F N(J R \times P M C)$ and AFS, while the second highest was found in genetic group $\mathrm{FN}(\mathrm{SL} \times \mathrm{PMC})$. As postpartum heat period is a reproductive trait not governed by additive type of gene action, the management and disease factors might contribute to a greater extend than the hereditary causes. The values obtained in the present study are in close agreement with the results reported by Chowdhury et al. (1994) in $\mathrm{FN} \times \mathrm{SL}$ cows of 154.8 days. Breed, exotic inheritance level in crossbred cows, the environment along with nutrition and management, might bring about variation of results.

Genetic group had highly significant $(p<0.001)$ effect on calving interval. Calving interval varied from 414.90 to 441.42 days in different genetic group of cows. The lowest and second lowest calving interval of cows were observed in genetic group PMC and $\mathrm{SL}(\mathrm{PMC} \times \mathrm{FN})$, respectively. The highest calving interval was noted in cows under genetic group AFS $\times$ PMC and $F N(J R \times P M C)$. The mean values of calving interval of this study were almost similar to the results reported by Bhuiyan (1999) in LO and in $\mathrm{FN} \times \mathrm{LO}$ as $431.70 \pm 9.29$ and $475.49 \pm 9.16$ days, respectively. Results of the present study were inconsistent with the findings of Uddin (2001), who reported that average calving intervals for
LO and $\mathrm{FN} \times \mathrm{LO}$ were $541.93 \pm 45.65$ and $534.29 \pm 37.64$ days, respectively. Although there was significant difference in calving interval among different genetic groups but the interval varied within very short range (only 27 days). It probably happened due to large number of cows in each group as well as very similar management under which the cows were kept.

\section{Conclusion}

According to the phenotypic value of lactation yield and SNF\%, the genetic group FN(J R $\times$ PMC) was superior to other groups but the lowest value observed for those traits in PMC genetic group. It is also important to note that the value of reproductive traits particularly service per conception, postpartum heat period and calving interval were found significantly lowest in PMC.

\section{References}

Bhuiyan AKFH and R Sultana (1994). Analysis of performance of exotic cattle breeds and their crosses in Bangladesh. Proceedings of the $5^{\text {th }}$ World Congress on Genetics Applied to Livestock Production 20: 355-358.

Bhuiyan MSA (1999). Estimation of genetic parameters for some economic traits of the dairy cattle. M.S Thesis, Department of Animal Breeding and Genetics, Bang. Agril. Univ., Mymensingh.

BLRI (Bangladesh Livestock Research Institute) (2001). An overview. Bangladesh Livestock Research Institute, Savar, Dhaka.

Chowdhury MZ, MJ Tahir and M Rafique (1994). Production performance and milk producing efficiency in different filial groups of Holstein Friesian $\times$ Sahiwal half-breds. Asian-Australasian Journal of Animal Sciences 7: 383-387.

Deb GK (2004). Estimation of genetic parameters of some quantitative traits in dairy cattle of Bangladesh. M.S. Thesis, Department of Animal Breeding and Genetics, Bang. Agril. Univ., Mymensingh.

Gunawardena A and LP Pushpakumara (1998). Performances of Holstein-Friesian cows in hill country of Srilanka. Indian Journal of Dairy Science 51: 202-203. 


\section{Performance of crossbred cows}

Hoque MA, MR Amin and MS Hossen (1999). Dairy potential of Pabna cows and crossbreds with Sahiwal and Friesian and within and between-breed sire effects. Asian-Australasian Journal of Animal Sciences 12: 161-164.

Hossain K B, S Takayanagi, T Miyake, K Moriya, AKFH Bhuiyan and Y Sasaki, (2002). Statistical genetic studies on cattle breeding for dairy productivity in Bangladesh: 1.Genetic improvement for milk performance of local cattle populations. Asian-Australasian Journal of Animal Sciences 15: 627-632.

Husain SS and KG Mostafa (1985). Reproductive potentialities of local and crossbred animals under farm and village condition. Livestock Adviser. 10: 15-19.

Islam MN, SMI Hussain and AKMA Mannan (1984). Studies on the physical parameters and chemical qualities on milk of BAU dairy farm and market milk in Mymensingh town. Bangladesh Journal of Animal Science 13: 52-55.

Islam SS and AKFH Bhuiyan (1997). Performance of crossbred Sahiwal at the Pabna milk shed area in Bangladesh. Asian-Australasian Journal of Animal Sciences 10: 581-586.

Khan UN, A Olsson, J Philipsson and K Hangsanet (1992). Sahiwal breed development in Pakistan. Proceedings of the sixth AAAP Animal Science Congress 1: 171-178.

Mantysaari EA (2002). Combining test day and full lactation records in prediction of breeding values. Proceedings of the $7^{\text {th }}$ World Congress on Genetics Applied to Livestock Production, August 19-23, Montpellier, France. P. 35-42.

Nahar N, M Islam and MA Hasnath (1992). A comparative study on the performance of $F_{1}$ crossbred cows under rural conditions. Asian-Australasian Journal of Animal Sciences 5: 435-438.

Padua JT and RG Silva (1996). Estimation of parameters and factors involved in the performance of crossbred Chiania $\times$ Nelore cattle. Animal Breeding Abstracts 64: 604.

Rahman MF, N Ahmed, and AR Ahmed (1987). A comparative study on some productive and reproductive performances of dairy cows at CCBDF, Savar, Dhaka. Bangladesh Veterinary J ournal 21: 55-61.

SAS (1991). Statistical analysis system for linear models, Third edition, SAS Institute Inc., Cary, North Carolina, USA.

Uddin MM (2001). A comparative study on some productive and reproductive economic traits of different genetic groups of dairy cows in military farm, Savar and Central cattle breeding and dairy farm, Savar, Dhaka. M.S. Thesis. Department of Dairy Science. Bang. Agril. Univ., Mymensingh.

Udo H MJ, C Hermans and F Dawood (1990). Comparison of two cattle production systems at Pabna district in Bangladesh. Tropical Animal Health Production 22: 247- 259. 